\title{
Crystallisation and Melting Behavior of Methyl Esters of Palm Oil
}

\author{
${ }^{1,2}$ Cheng Sit Foon, ${ }^{1}$ Yung Chee Liang, ${ }^{1}$ Noor Lida Habi Mat Dian, ${ }^{1}$ Choo Yuen May \\ ${ }^{2}$ Chuah Cheng Hock and ${ }^{1}$ Ma Ah Ngan \\ ${ }^{1}$ Engineering and Processing Research Division, Malaysian Palm Oil Board (MPOB) \\ 6 Persiaran Institusi, Bandar Baru Bangi, 43000 Kajang, Selangor, Malaysia \\ ${ }^{2}$ Department of Chemistry, Faculty of Science, University of Malaya \\ Lembah Pantai, 50603 Kuala Lumpur, Selangor
}

\begin{abstract}
The methyl esters of palm oil, which consists of saturated and unsaturated esters (0.6 to 95.9\% unsaturation) of the $\mathrm{C} 12$ to $\mathrm{C} 18$ fatty acids, solidify at the two temperature ranges, -52 to $-45^{\circ} \mathrm{C}$ and -24 to $21^{\circ} \mathrm{C}$, when the esters are cooled. When the esters are heated, they melt at two distinct temperatures, -25 and $-33^{\circ} \mathrm{C}$ and a broad peak at -9 to $28^{\circ} \mathrm{C}$. The heating thermograms also showed an exothermic crystallisation peak in between two endothermic melting peaks, indicating the occurrence of re-crystallisation of low melting methyl esters into higher melting point crystal and then melt again at higher temperature.
\end{abstract}

Key words: Differential scanning calorimetry, palm oil methyl esters

\section{INTRODUCTION}

Differential scanning calorimetry (DSC) measurement is a function of differential heat flow with temperature for compounds that exhibit thermal transitions such as melting and crystallisation ${ }^{[1]}$. This measurement provides qualitative and quantitative information about physical and chemical properties that involve endothermic and exothermic processes.

DSC has been widely used in the investigation of thermal behaviour of consumer products, especially in the food sector. For example, it is used to study the physical behaviour during processing procedure and storage of proteins, carbohydrates, fats and oils, alcohol and food packaging ${ }^{[2]}$. Unlike palm oil and palm oil products, which have been widely investigated using DSC for their thermal behaviour in finished food products, the application of DSC on palm oil methyl esters has not been reported extensively.

The crystallinity of the methyl esters of palm oil depends on the degree of unsaturation in the $\mathrm{C} 12$ to C18 alkyl chain of the fatty acid. Crystallinity of lipids has been studied by using DSC, which examines the crystallisation and also well as the melting behaviours ${ }^{[3-}$ 9] but such studies have largely been confined to investigations on triacylglycerols of edible oils, especially on their liquid fractions. On the contrary, few reports document the use of the technique to study the use of methyl esters of edible oils. Lee et al. ${ }^{[9]}$ used the technique to compare crystallisation behaviour of branched chain methyl esters of soybean and canola oils with their methyl esters. DSC technique was used as an analysis tool in the winterization study on methyl esters of soybean oil ${ }^{[10]}$ and waste cooking oil methyl esters $^{[11]}$.

In the present study, the thermal behaviour of palm oil methyl esters and their fractionated fractions was studied using DSC. The objective of the present study was to examine the effect of fatty acid composition (FAC) of palm oil methyl esters on their thermal behaviour.

\section{MATERIALS AND METHODS}

Distilled palm oil methyl esters were obtained from a local manufacturing company. Various fractions of palm oil methyl esters were obtained through fractionation steps. Pure methyl linoleate $(98.9 \%)$ and methyl oleate $(99.3 \%)$ were purchased from SigmaAldrich (M) Bhd.

Fatty acid composition analyses by gas chromatography: Fatty acid composition (FAC) of the samples used in the present study was analyzed using MPOB Test Method ${ }^{[12]}$. The method uses gas chromatography equipped with a flame ion detector and a very polar BPX 70 capillary column (bonded phase with fused silica) of $30 \mathrm{~m} \times 0.32 \mathrm{~mm}$ id. The following temperature programming was used: initial temperature: $100^{\circ} \mathrm{C}$, final temperature: $350^{\circ} \mathrm{C}$, injector temperature: $254^{\circ} \mathrm{C}$, detector temperature: $360^{\circ} \mathrm{C}$, rate: $10^{\circ} \mathrm{C} / \mathrm{min}$, carrier gas (Helium) at $2.0 \mathrm{~mL} / \mathrm{min}$.

Thermal analysis by differential scanning calorimetry (DSC): The crystallisation behavior of palm oil methyl esters and their fractionated saturated

Corresponding Author: $\quad$ Dr. Choo Yuen May, 6, Persiaran Institusi, Bandar Baru Bangi, 43000 Kajang, Selangor, Malaysia Tel: 603-89259592, Fax: 603-89262971 
and unsaturated fractions were analyzed using DSC. DSC analyses on the samples were performed using a Perkin Elmer DSC 7 instrument equipped with an Intracooler System II (Perkin Elmer, Norwalk, CT). Sample $\left( \pm 5 \mathrm{mg}\right.$ ) was completely melted at $50^{\circ} \mathrm{C}$ before weighed into an aluminium pan which was then sealed using a sample pan crimper. The sample was heated to $50^{\circ} \mathrm{C}$ in the instrument and held for $5 \mathrm{~min}$ to erase its previous thermal history. The sample was then cooled at a cooling rate of $5^{\circ} \mathrm{C} / \mathrm{min}$, from 50 to $-65^{\circ} \mathrm{C}$ for the cooling thermogram. The sample was then held at $65^{\circ} \mathrm{C}$ for $5 \mathrm{~min}$ before it was heated up to $50^{\circ} \mathrm{C}$ again at $5^{\circ} \mathrm{C} / \mathrm{min}$ for the melting thermogram.

\section{RESULTS AND DISCUSSION}

Table 1 shows the fatty acid composition (FAC) of fractionated palm oil methyl esters used in the present study. Samples with different FAC were used in order to study the thermodynamic behavior of the samples.

Crystallisation of Palm Oil Methyl Esters: The crystallisation peaks, total unsaturation and total saturation of fractionated palm oil methyl esters were tabulated in Table 2. Generally, there are two major and distinctive exothermic peaks (indicating crystallisation) present in the cooling thermograms. A typical cooling thermogram of palm oil methyl esters (Sample H) is as depicted in Fig. 1.

The first exothermic (crystallisation) peak can be denoted as the starting point of overall crystallisation process of methyl esters. For example, sample A (Tables 1 and 2), which contains high percentage of saturated methyl esters (95.92\%), with methyl palmitate $(92.80 \%)$ as the pre-dominant compound, there is only one crystallisation peak present in the thermogram occurring at temperature $20.5^{\circ} \mathrm{C}$. An increase in unsaturated methyl esters in sample B to $10.9 \%$ has brought significant changes to the thermogram. It was observed that there was a small peak (second exothermic / crystallisation peak) occurred at $-47.8^{\circ} \mathrm{C}$ while the first peak of the crystallisation was shifted to $16.5^{\circ} \mathrm{C}$. It can be deduced that the first exothermic peak in the thermogram, occurring at higher temperature, is the crystallisation peak for saturated methyl esters while the second exothermic peak at lower temperature is the result of crystallisation of unsaturated methyl esters. This observation is similar to that exhibited in the cooling thermogram of palm oil, where there are two distinctive peaks, one for the stearin and one for the olein fraction ${ }^{[13]}$.

It was also noted that the occurrence of the first crystallisation peak depends very much on the content of saturated methyl esters. As the percentage of saturated methyl esters decreases, the crystallisation temperature of the first exothermic peak also decreases accordingly (Table 2). Samples with high percentages of saturated methyl esters tend to crystallize at higher temperature than samples with low percentages of saturated methyl esters.

As the composition of unsaturated methyl esters increases to $50.6 \%$ (as in sample $\mathrm{H}$ ), it was noticed that the first crystallisation peak was further shifted to $7.48^{\circ} \mathrm{C}$. The second crystallisation peak, however, does not show significant shift. The size of the second peak, however, was found to increase proportionally with increment in unsaturated methyl esters content. With further reduction in saturated methyl esters (mainly methyl palmitate) as exhibited by sample Q, which contains $11.2 \%$ saturated methyl esters; the first crystallisation peak was further shifted to $-20.7^{\circ} \mathrm{C}$.

All the samples studied showed that the second crystallisation peak does not shift significantly as compared to the first crystallisation peak. This was supported by the evidence in sample T $(99.3 \%$ methyl oleate) which showed only a single crystallisation peak at $48.9^{\circ} \mathrm{C}$ (Fig. 2). The overall mean value for the second crystallisation peak occurred at $-48.413 \pm$ $2.212^{\circ} \mathrm{C}$ regardless of the percentage of saturated methyl esters.

Melting of palm oil methyl esters: Unlike the sharp crystallisation peaks occurred in the cooling thermogram, the endothermic peaks of the fractionated methyl esters samples were recorded as broad peaks. A typical of the heating thermogram is as depicted in Fig. 3 (Sample H). Generally, there were three major endothermic peaks in the thermogram as compared to two sharp peaks in the crystallisation thermogram. Table 3 depicts the total saturation and total unsaturation of the fractionated palm oil methyl esters and their endothermic peaks.

The endothermic peaks are correlated to the melting point of individual methyl ester (Table 4). For example, sample A (Tables 1 and 3), contains mainly methyl palmitate $(92.8 \%)$ and there was only one broad endothermic peak at $27.5^{\circ} \mathrm{C}$. For fractionated samples containing mixture of saturated and unsaturated methyl esters (from samples B to U), there was one broad endothermic peak at higher temperature range; and two melting peaks and a crystallisation peak at lower temperature range. From the heating thermograms of methyl oleate (sample T, 99.3\% purity) (Fig. 4) and methyl linoleate (sample U, $98.9 \%$ purity) (Fig. 5), it was found that both methyl oleate and methyl linoleate exhibited an endothermic peak at -19.3 and $-41.5^{\circ} \mathrm{C}$, respectively. The recorded endothermic peaks were in close agreement with their melting points, which were 20 and $-41^{\circ} \mathrm{C}$, respectively.

An interesting melting behaviour was noted for fractionated palm oil methyl esters. There were two melting transitions and one crystallisation transition recorded in the heating thermogram (Fig. 3). 


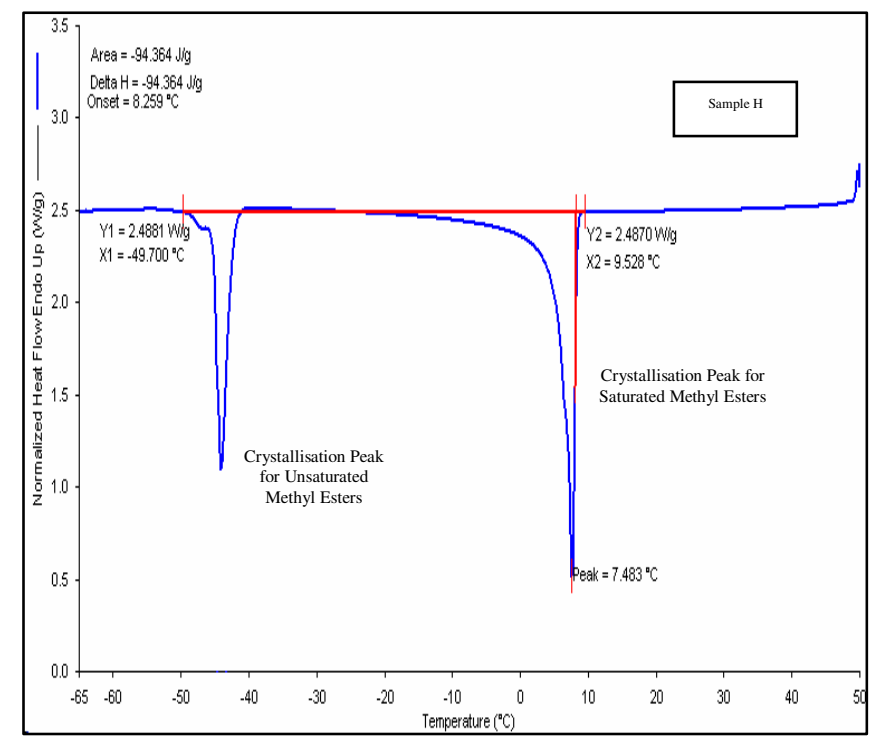

Fig. 1: Typical cooling thermogram

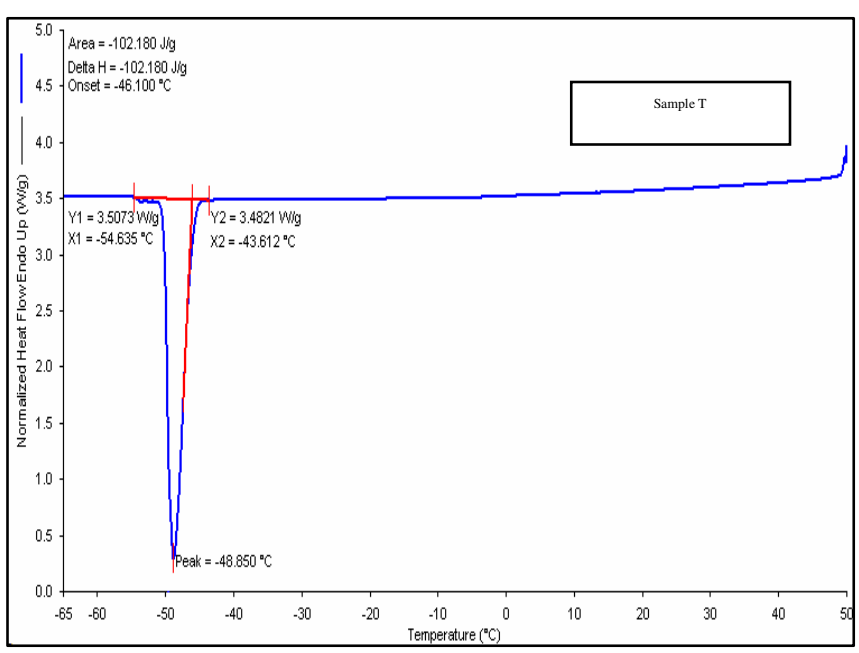

Fig. 2: Cooling Thermogram of methyl oleate

An interesting melting behaviour was noted for fractionated palm oil methyl esters. There were two melting transitions and one crystallisation transition recorded in the heating thermogram (Fig. 3). This observation is due to the occurrence of simultaneous melting and crystallisation of the individual palm oil methyl esters in the samples. For example, between -35 to $-32^{\circ} \mathrm{C}$, the crystallized methyl oleate (melting point, $20^{\circ} \mathrm{C}$ ) started to melt while the melted methyl linoleanate (melting point, $-52^{\circ} \mathrm{C}$ ) and methyl linoleate (melting point, $-35^{\circ} \mathrm{C}$ ) started to re-crystallize into the higher melting point crystal and then melted together at a higher temperature $\left(-24.3^{\circ} \mathrm{C}\right)$. As a result, the melting point region is a superposition of two melting peaks and one crystallisation peak. This phenomenon may be due

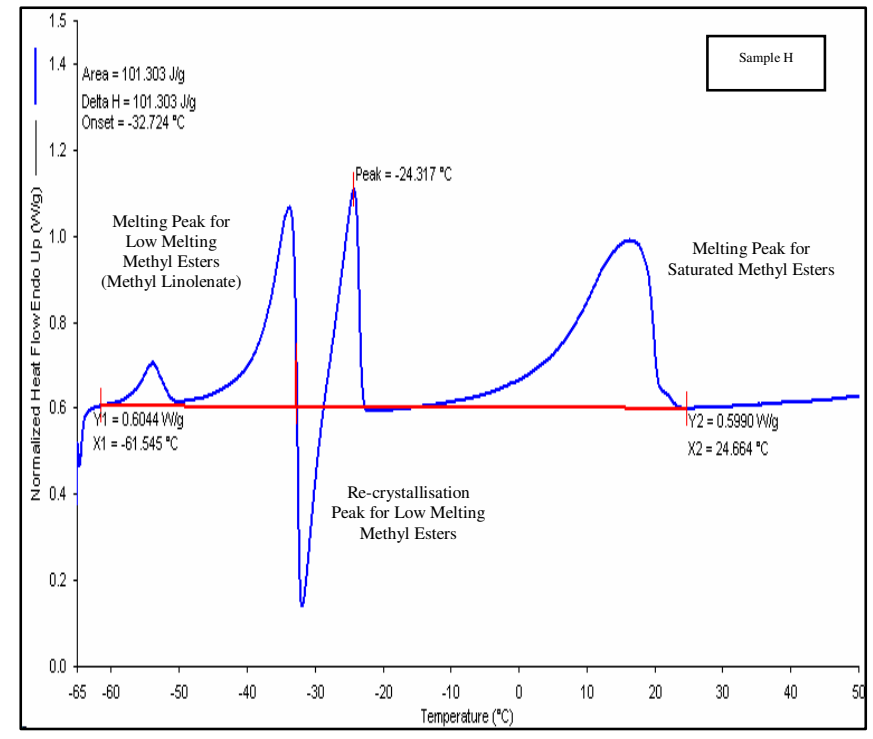

Fig. 3: Typical heating thermogram

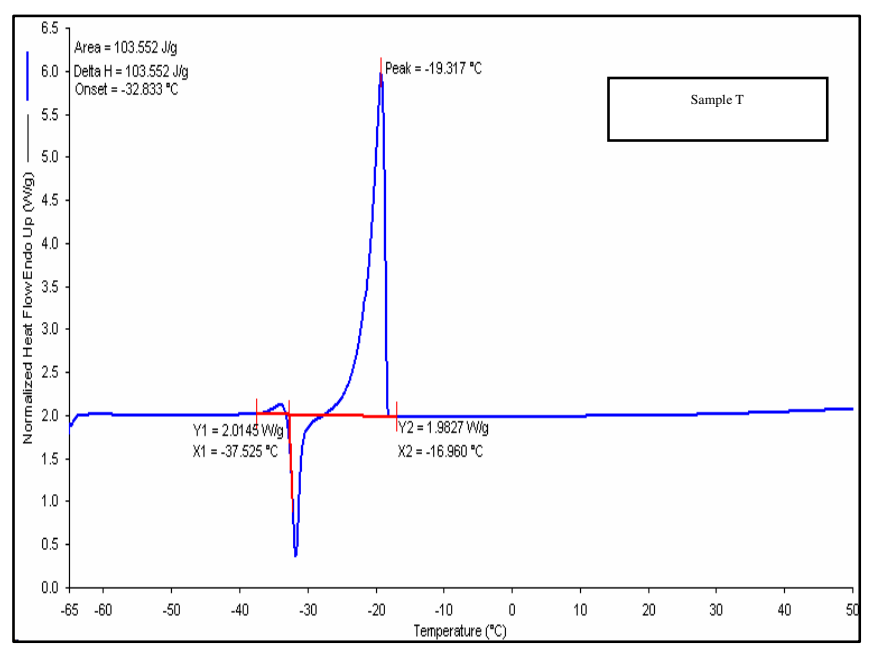

Fig. 4: Heating thermogram of methyl oleate

to the inter-trapping of methyl oleate (a higher melting component) in methyl linoleate and methyl linolenate crystals network). Another possibility is due to the reorientation or transformation of the crystals structures of methyl linoleanate and methyl linoleate to different melting points.

The two melting transitions of fractionated palm oil methyl esters were consistently occurred at $-33.376 \pm$ $0.677^{\circ} \mathrm{C}$ and $-24.880 \pm 1.303^{\circ} \mathrm{C}$, respectively (Table 3 ). The occurrence of a third melting peak is dependent on the composition of saturated methyl esters in the sample, which is generally recorded as a broad peak. It was noted that a decrease in the percentage of total saturated methyl esters in the sample, particularly the content of methyl palmitate (Tables 1 and 3), would shift the third endothermic peak to a lower temperature. 
Am. J. Appl. Sci., 3 (5): 1859-1863, 2006

Table 1: $\quad$ Fatty acid compositions of fractionated palm oil methyl esters

Sample Fatty Acid Composition (FAC) (as \% methyl esters)

$\begin{array}{lrrrrrrrrrrr} & \text { C12:0 } & \text { C14:0 } & \text { C16:0 } & \text { C16:1 } & \text { C18:0 } & \text { C18:1 } & \text { C18:2 } & \text { C18:3 } & \text { C20:0 } & \text { Total } \\ \text { Saturation }(\%) & \text { Total } \\ \text { Unsaturation (\%) }\end{array}$

Table 2: Cooling peaks of fractionated palm oil methyl esters

\begin{tabular}{|c|c|c|c|c|c|c|}
\hline \multirow[b]{2}{*}{ Sample } & \multirow[b]{2}{*}{ Total Saturation (\%) } & \multirow[b]{2}{*}{ Total Unsaturation (\%) } & \multicolumn{2}{|c|}{ Exothermic Peaks $\left({ }^{\circ} \mathrm{C}\right)$} & \multirow[b]{2}{*}{2} & \multirow[b]{2}{*}{$2 \mathrm{a}$} \\
\hline & & & 1 & $1 \mathrm{a}$ & & \\
\hline$\overline{\mathrm{A}}$ & 95.92 & 4.08 & 20.483 & 13.571 & - & - \\
\hline $\mathrm{B}$ & 89.07 & 10.93 & 16.500 & - & -47.826 & - \\
\hline $\mathrm{C}$ & 79.83 & 20.17 & 17.483 & $-2.619,-1.429$ & -50.238 & - \\
\hline $\mathrm{D}$ & 71.38 & 28.62 & 11.316 & - & -46.667 & - \\
\hline $\mathrm{E}$ & 68.47 & 31.53 & 16.150 & - & -50.000 & - \\
\hline $\mathrm{F}$ & 62.05 & 37.95 & 13.316 & - & -51.304 & - \\
\hline $\mathrm{G}$ & 58.03 & 41.97 & 12.650 & - & -53.696 & - \\
\hline $\mathrm{H}$ & 49.41 & 50.59 & 7.483 & - & -47.317 & -44.146 \\
\hline I & 40.05 & 59.95 & 4.816 & - & -50.435 & - \\
\hline $\mathrm{J}$ & 37.37 & 62.63 & 2.174 & 0.435 & -47.500 & - \\
\hline $\mathrm{K}$ & 31.71 & 68.29 & 0.000 & -1.860 & -45.184 & - \\
\hline $\mathrm{L}$ & 30.05 & 69.95 & -0.517 & -2.174 & -51.333 & - \\
\hline $\mathrm{M}$ & 26.18 & 73.82 & -4.878 & -8.780 & -47.684 & - \\
\hline $\mathrm{N}$ & 21.31 & 78.69 & -7.174 & -11.600 & -46.850 & - \\
\hline $\mathrm{O}$ & 16.30 & 83.70 & -13.023 & - & -47.017 & - \\
\hline $\mathrm{P}$ & 12.80 & 87.20 & -16.744 & - & -47.184 & - \\
\hline Q & 11.15 & 88.85 & -20.731 & - & -46.500 & - \\
\hline $\mathrm{R}$ & 10.63 & 89.37 & -21.463 & - & -47.017 & - \\
\hline $\mathrm{S}$ & 9.85 & 90.15 & -23.171 & - & -47.684 & - \\
\hline $\mathrm{T}^{*}$ & 0.66 & 99.34 & - & - & -48.850 & - \\
\hline $\mathrm{U}^{* *}$ & 1.11 & 98.89 & - & - & - & - \\
\hline
\end{tabular}

Table 3: $\quad$ Melting peaks of fractionated palm oil methyl esters

\begin{tabular}{|c|c|c|c|c|c|c|}
\hline \multirow[b]{2}{*}{ Sample } & \multirow[b]{2}{*}{ Total Saturation (\%) } & \multirow[b]{2}{*}{ Total Unsaturation (\%) } & \multicolumn{4}{|c|}{ Endothermic Peak $\left({ }^{\circ} \mathrm{C}\right)$} \\
\hline & & & 1a & 1 & 2 & 3 \\
\hline $\mathrm{A}$ & 95.92 & 4.08 & - & - & - & 27.516 \\
\hline B & 89.07 & 10.93 & - & -33.261 & -26.522 & 25.516 \\
\hline $\mathrm{C}$ & 79.83 & 20.17 & - & -33.542 & - & 25.016 \\
\hline D & 71.38 & 28.62 & - & -33.902 & -24.286 & 21.350 \\
\hline E & 68.47 & 31.53 & - & -33.043 & -25.600 & 25.516 \\
\hline $\mathrm{F}$ & 62.05 & 37.95 & - & -33.262 & -26.522 & 23.016 \\
\hline G & 58.03 & 41.97 & - & -33.043 & -26.739 & 22.350 \\
\hline $\mathrm{H}$ & 49.41 & 50.59 & -53.902 & -34.390 & -24.317 & 15.854 \\
\hline I & 40.05 & 59.95 & - & -32.650 & -23.261 & 16.522 \\
\hline $\mathrm{J}$ & 37.37 & 62.63 & - & -32.484 & -24.348 & 12.826 \\
\hline K & 31.71 & 68.29 & -52.791 & -33.484 & -24.186 & 9.767 \\
\hline $\mathrm{L}$ & 30.05 & 69.95 & - & -32.317 & -24.378 & 9.565 \\
\hline M & 26.18 & 73.82 & - & -34.317 & -27.619 & 4.286 \\
\hline $\mathrm{N}$ & 21.31 & 78.69 & - & -32.484 & -24.130 & 4.130 \\
\hline $\mathrm{O}$ & 16.30 & 83.70 & - & -33.484 & -25.208 & -1.250 \\
\hline $\mathrm{P}$ & 12.80 & 87.20 & -53.488 & -33.65 & -25.116 & -4.186 \\
\hline Q & 11.15 & 88.85 & -54.390 & -33.902 & -23.415 & -5.122 \\
\hline $\mathrm{R}$ & 10.63 & 89.37 & - & -33.659 & -23.415 & -5.854 \\
\hline $\mathrm{S}$ & 9.85 & 90.15 & - & -33.902 & -23.902 & -8.537 \\
\hline $\mathrm{T}^{*}$ & 0.66 & 99.34 & - & -34.048 & -19.317 & - \\
\hline $\mathrm{U}^{* *}$ & 1.11 & 98.99 & - & -41.484 & - & - \\
\hline
\end{tabular}

Notes: *methyl oleate; **methyl linoleate; 1a indicates a shoulder peak. 


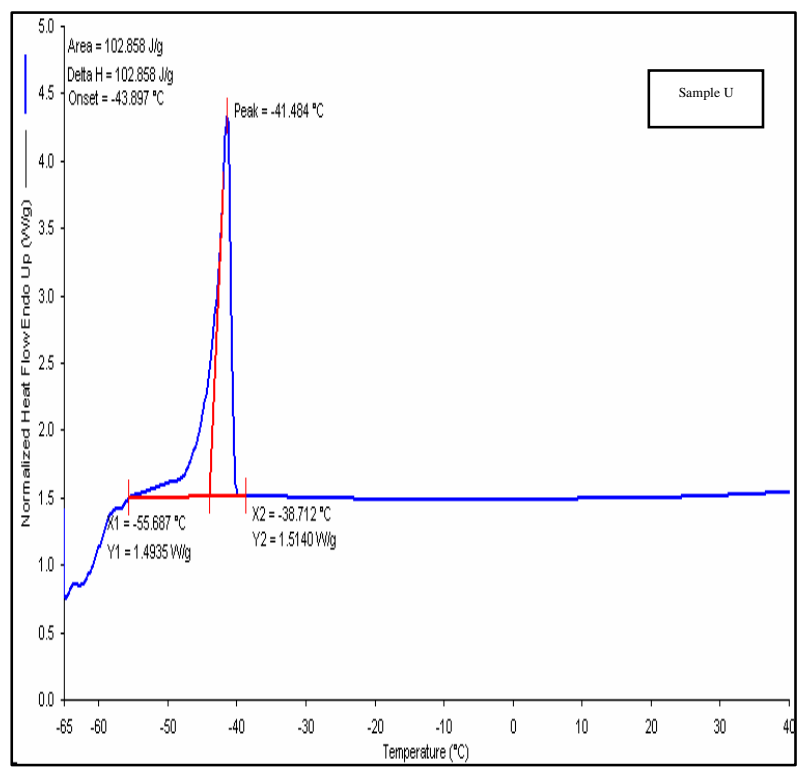

Fig. 5: Heating thermogram of methyl linoleate

Table 4: Melting points of individual methyl ester

\begin{tabular}{lc}
\hline Methyl Esters & Melting Point $/{ }^{\circ} \mathrm{C}$ \\
\hline Methyl Laurate (C12:0) & 5 \\
Methyl Myristate (C14:0) & 18.5 \\
Methyl Palmitate (C16:0) & 30.5 \\
Methyl Stearate (C18:0) & 39.1 \\
Methyl Oleate (C18:1) & -20 \\
Methyl Linoleate (C18:2) & -35 \\
Methyl Linolenate (C18:3) & -52 \\
Methyl Arachidate (C20:0) & - \\
\hline Source: Gunstone et al $^{[15]}$ &
\end{tabular}

\section{ACKNOWLEDGEMENT}

The authors would like to thank Tan Sri Datuk Dr. Yusof Basiron, the former Director General of Malaysian Palm Oil Board (MPOB) for his permission to publish this paper.

\section{REFERENCES}

1. Impact Analytical, Applications of Differential Scanning Calorimetry, www.impactanalytical.com/pdfs/notes/dsc.pdf

2. Behlau, L. and G. Widmann, 2003. Collected Applications: Thermal Analysis, Food, Mettler Toledo, Switzerland.

3. Chong, C.L., 2001. Crystallisation of Palm Oil Products. In: Crystallisation and Solidification Properties of Lipids (Eds. N. Widlak, R. Hartel and S. Narine) pp: 110-119. AOCS Press, Illinois.
4. Ollivon, M., C. Loisel, C. Lopez, P. Lesieur, F. Artzer and G. Keller, 2001. Simultanenous Examination of Structural and Thermal Behaviours of Fats by Coupled X-ray Diffraction and Differential Scanning Calorimetry Techniques: Application to Cocoa Butter Polymorphism. In: Crystallisation and Solidification Properties of Lipids (Eds. N. Widlak, R. Hartel and S. Narine) pp: 34-41. AOCS Press, Illinois.

5. Tan, C.P. and Y.C. Man, 2003. Analysis of Edible Oils by Differential Scanning Calorimetry. In: Advances in Lipid Methodology - Five (Eds. R.O. Adlof) pp: 1-42. The Oily Press, Illinois.

6. Oh, F.C.H., 1985. Thermal analysis of palm oil and other oils. PORIM Bull., 11: 24-33. Malaysian Palm Oil Board, Selangor, Malaysia.

7. Che, M.Y.B. and P.Z. Swe, 1995. Thermal analysis of failed-batch palm oil by differential scanning calorimetry. J. Am. Oil Chemists' Soc., 72: 1529-1532.

8. Siew, W.L. and F.M. Jaafar, 2000. Compositional and differential scanning calorimetry (DSC) studies of crystals of palm olein. J. Oil Palm Res., 12: 1-13.

9. Lee, I., L.A. Johnson and E.G. Hammond, 1995. Use of branched-chain esters to reduce the crystallisation temperature of biodiesel. J. Am. Oil Chemists' Soc., 72: 1155-1160.

10. Lee, I., L.A. Johnson and E.G. Hammond, 1996. Reducing the crystalization temperature of biodiesel by winterizing methyl soyate. J. Am. Oil Chemists' Soc., 73: 631-636.

11. González Gómez, M.E., R. Howard-Hildige, J.J. Leahy and B. Rice, 2002. Winterization of waste cooking oil methyl ester to improve cold temperature fuel properties. Fuel, 81: 33-9.

12. Malaysian Palm Oil Board, 2005. MPOB test methods: A compendium of test on palm oil products, palm kernel products, fatty acids, food related products and others. Malaysian Palm Oil Board, Selangor, pp: 310-317.

13. DeMan, L. and J.M. deMan, 1995. DSC: A tool in the evaluation of fats and fat products. J. Malaysian Oil Sci. Technol., 7: 17-26.

14. Gunstone, F.D., J.L. Harwood and F.B. Padley, 1994. Lipid Handbook. 2nd Edn. Chapman and Hall, London. 